\title{
Construction of an Experimental Chemistry Platform at Agricultural University
}

\author{
http://dx.doi.org/10.3991/ijoe.v10i6.3882 \\ Ying Fu and Fei Ye \\ Northeast Agricultural University, Harbin, P.R. China
}

\begin{abstract}
To address Agricultural University's courses on the characteristics of chemical experiments, we designed an experimental chemistry platform. The platform includes modules on teaching resources, self-tests, interaction, and virtual experiments to build a user-friendly learning environment for the students. It was shown that the interactive teaching model engaged the students' interest and helped them strengthen the quality of their scientific research understanding and innovation.
\end{abstract}

Index Terms-Construction; Experimental chemistry; Website

\section{INTRODUCTION}

The basic chemistry experiment course at Agricultural University is a majors course for agriculture science, food science, veterinary medicine science, environmental science, and life science $[1,2]$. It emphasizes training in basic experimentation skills and utilizing basic knowledge about chemistry as well as focuses on the combination of related knowledge for the follow-up courses. Teaching online has become a mainstream means of modern education because students can find a lot of information through the Internet $[3,4]$. Therefore, using Internet resources to facilitate students' learning and to stimulate enthusiasm for learning is very important $[5,6]$. In order to share teaching achievements and teaching resources, we constructed a basic chemistry experiment platform.

\section{THE CHARACTERISTICS OF CHEMISTRY EXPERIMENT NETWORK PLATFORM}

The traditional method of teaching basic chemistry experiments at Agricultural University is face-to-face through demonstrating the methods and describing the experimental techniques. As an independent laboratory, such a teaching method provides limited operational demonstration and a small amount of information, making it difficult to achieve student-centered teaching. However, the basic experimental chemistry network platform uses multimedia technology based on the principle of autonomy. It emphasizes the integration of knowledge and information resources and reflects the openness, interactivity, compatibility, and efficiency for combining and consolidating teaching information. The web platform presents the latest advanced technology processes, ideas and concepts for the students to achieve the best learning results. The basic chemistry network platform is completely open and easy to access at any time without logging in. The design principles are as follows: (1) Interaction, students can independently preview and review information through the platform outside of school. (2) Simulation, students can complete the experiments, simulate actual operating results and watch the experimental phenomenon by clicking mouse. (3) Richness, the network teaching platform includes all of the teaching content. (4) Resources, it is easy and quick to search the network teaching platform's large number of resources, such as databases, pictures and software. (5) Networking, the platform is built on a network extending in all directions to maximize the space for students [7].

Each course has five functional modules (course introduction, unit operation, course selection, tool box and contact us) to facilitate the students' previewing, reviewing and self-teaching [8]. The home page is shown in Fig. 1 .

The five modules can not only satisfy the needs of students for learning but can also provide a variety of resources, such as simulation experiments, chemical data, charts, pictures, software, and so on. The assignments can be finished online through self-tests and after-school selfexamination via the examination system. Effective interaction is attained between the students and teacher by using the answer system and the email system. Teachers can answer questions from different students in real time, and simulation experiments can be completed through the virtual laboratory.

\section{THE DESIGN OF EXPERIMENT MODULE}

The design of the experimental teaching module is based on the well-conceived link structure of the site, the different functions of the site, and the module-level division. The platform shows users a clear idea of its function and structure, which enhances the usability. We designed the chemistry teaching modules to meet the requirements of teaching. The structure of the teaching module is shown in Fig. 2.

We built a virtual simulation laboratory and established two new platforms: the confirmatory virtual experimental platform and the interactive virtual simulation experimental platform. (1) The confirmatory virtual experimental platform combines the basic experimental operation and confirmatory experiment by using self-developed chemistry experimental software. Through video images, students are able to understand the experimental principles and observe the phenomenon clearly. The platform achieved better teaching and learning results. (2) The interactive virtual simulation experimental platform is based on automatic simulation technology with the use of its powerful graphical function and online help function for establishing the virtual reality graphics. Students are able to install and dismantle the instrument by clicking a mouse. The experimental phenomena can be realistically 


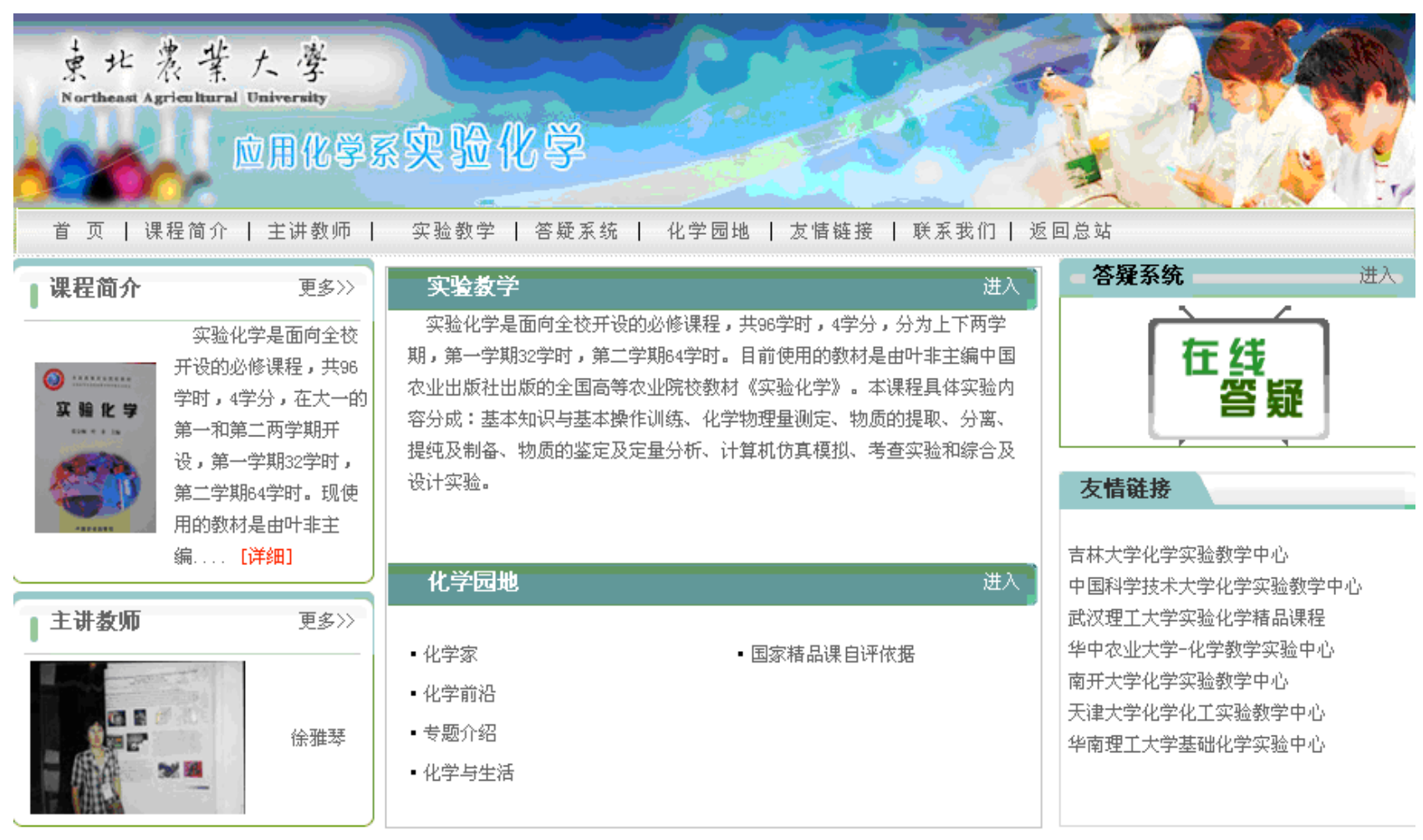

Figure 1. The interface of experimental chemistry

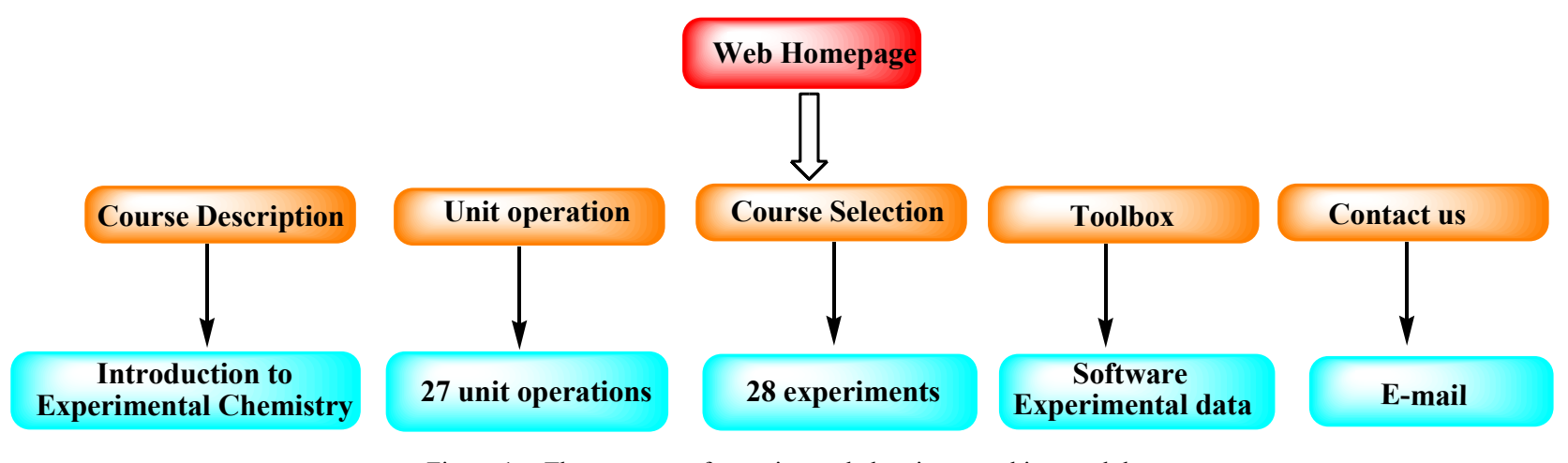

Figure 1. The structure of experimental chemistry teaching module

observed. The process is described with text and voice prompts, so if the students' manipulation is wrong, the platform displays "error" and the correct operation is shown to help the students install the instrument in the correct way. The phenomena of flame, smoke, boiling liquid and drop down in experiment are very realistic. Additionally, the instrument can be enlarged, reduced and rotated $360^{\circ}$ to be observed from any direction. The virtual simulation experimental instrument is shown in Fig. 3.

\section{CONCLUSION}

The basic experimental chemistry platform works well and has been praised by teachers and students. It is playing an important role in improving the teaching quality of experimental chemistry and continues to undergo modification and improvement.

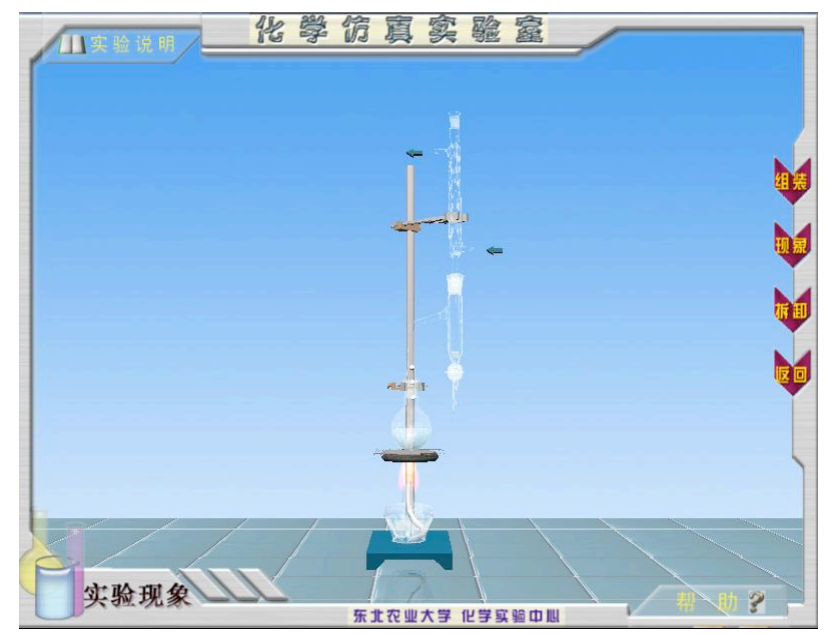

Figure 2. The Virtual Simulation Experiment 


\section{SHORT PAPER}

\section{CONSTRUCTION OF EXPERIMENT CHEMISTRY PLATFORM IN AGRICULTURAL UNIVERSITY}

\section{REFERENCES}

[1] J.W. Bai, Y.Q. Xu, F. Ye, "The development of organic chemistry experimental software in agricultural university," Higher Agricultural Education, vol213, pp.64-66, March 2009

[2] J.W. Bai, F. Ye,Y.Q. Xu, "The Design and Arrangement of Multimedia Courseware on Agro-organic Chemistry Experiment Operation," Higher Education in Chemical Engineering, vo196, pp4042, April 2007

[3] Y. Fu, F. Ye, "Construction and Practice of Green Chemical Experiment in Agriculture University," Research and Exploration in Laboratory. Vol27, pp137-139, May 2008.

[4] Y. Fu, Y.Q. Xu, F. Ye, "The probe of innovation of organic chemical experiment course in agricultural university," Laboratory Science. Vol4, pp58-60, August 2009

[5] H. Liu, S.Y. Wang, Design and Implementation of Network Virtual Teaching System Based on Silverlight. Modern Educational Technology, Vol 19, pp. 114-116, October 2009

[6] X.P. Huang, Y.G. Yi, X.S. Wang, C.B. Yu, Study on Construction Method of Virtual Teaching System Based on Internet. Journal of
Tianjin Institute of Urban Construction, Vol 14, pp.64-67, January 2008

[7] F. Ye, The Develop and Design of Experimental Chemistry Website. Computers and Applied Chemistry, Vol 25, pp.120-122, January 2008

[8] http://202.118.167.91/dahua/kcsz/syhx/default.asp

\section{AUTHORS}

Ying Fu is with the College of Science, Northeast Agricultural University, Harbin, P.R. China (e-mail: fuying@ neau.edu.cn).

Fei Ye is with the College of Science, Northeast Agricultural University, Harbin, P.R. China. He is the corresponding author. (e-mail: yefei@neau.edu.cn).

This work was supported by Heilongjiang Province New Century Higher Education Reform Project. Submitted 15 May 2014. Published as resubmitted by the authors 25 October 2014. 